

\title{
Trends in prevalence of cerebral palsy in children born with a birthweight of 2,500 g or over in Europe from 1980 to 1998
}

Elodie Sellier, Geraldine Surman, Kate Himmelmann, Guro Andersen, Allan Colver, Ingeborg Krägeloh-Mann, Javier De-La-Cruz, Christine Cans

\section{To cite this version:}

Elodie Sellier, Geraldine Surman, Kate Himmelmann, Guro Andersen, Allan Colver, et al.. Trends in prevalence of cerebral palsy in children born with a birthweight of 2,500 g or over in Europe from 1980 to 1998. European Journal of Epidemiology, 2010, 25 (9), pp.635-642. 10.1007/s10654-010-9474-0 . hal-00598959

\section{HAL Id: hal-00598959 \\ https://hal.science/hal-00598959}

Submitted on 8 Jun 2011

HAL is a multi-disciplinary open access archive for the deposit and dissemination of scientific research documents, whether they are published or not. The documents may come from teaching and research institutions in France or abroad, or from public or private research centers.
L'archive ouverte pluridisciplinaire HAL, est destinée au dépôt et à la diffusion de documents scientifiques de niveau recherche, publiés ou non, émanant des établissements d'enseignement et de recherche français ou étrangers, des laboratoires publics ou privés. 
Trends in Prevalence of Cerebral Palsy in Children born $\geq 2500 \mathrm{~g}$ in Europe from 1980 to 1998.

Elodie Sellier MD, ${ }^{1}$ Geraldine Surman BSc MSc, ${ }^{2}$ Kate Himmelmann MD PhD,${ }^{3}$ Guro Andersen MD, ${ }^{4,5}$ Allan Colver MD, ${ }^{6}$ Ingeborg Krägeloh-Mann MD, ${ }^{7}$ Javier De-la-Cruz MD, ${ }^{8}$ Christine Cans MD PhD. ${ }^{1}$

1. TIMC/ThEMAS-RHEOP, Grenoble University Hospital, Grenoble, France

2. National Perinatal Epidemiology Unit, University of Oxford, United Kingdom

3. Queen Silvia Children's Hospital/Sahlgrenska University Hospital, Gothenburg, Sweden

4. Norwegian Cerebral Palsy Registry, Habilitation Center, Vestfold Hospital, Tonsberg, Norway

5. Department of Laboratory Medicine, Children's and Women's Health, Norwegian University of Science and Technology, Trondheim, Norway

6. Newcastle University, Newcastle upon Tyne, United Kingdom

7. Department of Paediatric Neurology and Developmental Medicine, University Children's Hospital, Tübingen, Germany

8. Clinical Research Unit i+12, CIBERESP, 12 de Octubre University Hospital, Madrid, Spain

Correspondence to Christine Cans

Public Health Department, Pavillon Taillefer, Centre Hospitalier Universitaire BP 217, 38043

Grenoble, cedex 9, France.

Tel: (+33) $476769403 \quad$ Fax: (+33) 476768831

E-mail: CCans@chu-grenoble.fr 


\begin{abstract}
Time trends for cerebral palsy $(\mathrm{CP})$ prevalence in children born $\geq 2500 \mathrm{~g}$ vary across studies and scarce data exist on trends by subtype of CP. The objective of this study was to describe changes in prevalence of CP in infants born $\geq 2500 \mathrm{~g}$ between 1980 and 1998 in Europe. Data were collated from the SCPE (Surveillance of Cerebral Palsy in Europe collaboration) common database. Poisson regression was used to test for change in prevalence over time. Birth year and register effects were explored and trends in prevalence were estimated by $\mathrm{CP}$ subtype and severity. Four thousand and two children with CP and birthweight $\geq 2500 \mathrm{~g}$ were recorded in 15 population based-registers. The overall prevalence of $\mathrm{CP}$ was 1.16 per 1000 live births $(0.88-1.48)$ in 1980 and 0.99 (CI, 0.80-1.20) in 1998. The trend was not significant $(P=.14)$, except in two registers. However, there were significant changes in the prevalence of spastic CP subtypes, with a decrease in the bilateral spastic form $(P<.001)$, and an increase in the unilateral spastic form $(P=.004)$. There was a concurrent reduction in neonatal mortality from 1.7 (CI, 1.4-2.1) to 0.9 (CI, 0.7-1.1) per 1000 live births with birthweight $\geq 2500 \mathrm{~g}$. In conclusion, for children born with birthweight $\geq 2500 \mathrm{~g}$, the prevalence of CP in Europe was stable in spite of changes by subtype and a significant decrease in neonatal mortality.
\end{abstract}

Keywords: Cerebral palsy, Children with birthweight $\geq 2500$ g, Europe, Prevalence, Statistical interaction. 


\section{INTRODUCTION}

Cerebral palsy $(\mathrm{CP})$ is the most common cause of significant motor impairment in children. Approximately 2 children in every 1000 born alive suffer from CP. Although the risk of having $\mathrm{CP}$ is greatly increased for those born very preterm or with very low birthweight,[1] children with birthweight $\geq 2500 \mathrm{~g}$, what we shall call normal birthweight (NBW) for the purpose of this paper still account for most children affected. More than half of the children born during the 1970s and 1980s with CP and recorded on a European database, weighed more than $2500 \mathrm{~g}$ at birth;[2] the situation is similar in the USA[3], Australia [4] or China. [5]

Less research has been carried out on the epidemiology of CP in children of NBW than in those of very low birthweight $(<1500 \mathrm{~g})$. As the number and severity of impairments increase with increasing gestational age $[6,7]$ and birthweight, $[8]$ the type of brain lesion among term or NBW children tends to exhibit a different pattern to that of preterm or low birthweight births.[9-11] Time trends for CP prevalence in NBW children vary across studies.[12, 13] Most of them reported stable prevalence rates from the 1970s to the 1990s. [4, 14-17] However, a small increase was reported in USA between 1975 and 1991 [18] while in Sweden the monitoring from the 1950s to the 1990s showed an increase in prevalence from the beginning of the 1970s to the mid 1980s followed by a decrease. [19] Also, in Iceland a decrease in prevalence for term babies was observed in 1997-2003 in comparison with 19901996. [20]

In 1998, a network of population-based CP registers, Surveillance of Cerebral Palsy in Europe (SCPE),[21] was established. It is the largest international collaboration of CP 
registers in the world. Anonymous data, now covering 19 registers, are held in the common database. Data are recorded and coded according to agreed definitions.[22]

This paper aims to establish whether the prevalence of CP in NBW children altered in Europe between 1980 and 1998 using multicentre analysis methods. Reporting of secular trends for main neurologic subtypes and severity of impairment were also made possible as a result of the large database available. 


\section{MATERIAL AND METHODS}

\section{Definition and classification}

All registers contributing to the network are population-based, covering either a region or a whole country. Data were collated from SCPE common database as described previously.[2, 21] CP is defined as a group of permanent, but not unchanging, disorders of movement and/or posture and of motor function, due to a non-progressive interference, lesion, or abnormality of the developing/immature brain. Progressive motor disorders, nerve or muscular diseases and brain metabolic disorders are excluded. The diagnosis of $\mathrm{CP}$ is confirmed at around age 5 years, before submission by each register of its data to the SCPE common database. Subtypes of CP are defined as unilateral spastic, bilateral spastic, dyskinetic or ataxic. Hierarchic trees developed by SCPE were used to implement inclusion and exclusion criteria and classify $\mathrm{CP}$ subtypes consistently among registers. $[2,21]$

\section{Study population}

Children with CP born from 1980 to 1998 , whose mothers lived in an area covered by a contributing register at birth, were eligible for this study. We selected children with birthweight $\geq 2500$ g. Post-neonatal CP cases were excluded. Annual population data for live births, stratified by birthweight were provided by each register except four, for which these data were not available by birthweight (SCPE_C02 in Toulouse, France; SCPE_C07 in Dublin, Ireland; SCPE_C14 in Arnhem, Netherlands and SCPE_C21 in Lisbon, Portugal). Data from these four registers were consequently excluded from analysis. One register, SCPE_C10 in Tübingen, Germany, recorded only bilateral spastic CP cases and its data were included only when analyzing the bilateral spastic subgroup. The SCPE_C01 register in 
Grenoble, France, has specific migration patterns and cases were defined as living in the area at the time of registration.

\section{Characteristics of the children}

Classification of CP subtypes followed SCPE classification.[22],[23] Severe intellectual impairment was defined as IQ below 50; epilepsy as a history of two unprovoked seizures before confirmation of CP diagnosis, excluding febrile or neonatal seizures; severe visual impairment as visual acuity of $<6 / 60$ (Snellen scale) or 0.1 (Decimal scale) in the better eye following correction and severe hearing impairment as a loss of $>70 \mathrm{~dB}$ in the better ear before correction. Severity of CP was assigned to three categories.[24] Severe CP was defined as children with IQ $<50$ and unable to walk, even with assistive devices. Moderate CP was defined as children with IQ $<50$ and able to walk; or children with IQ $\geq 50$ and unable to walk without assistive devices. Mild CP was defined as children with IQ $\geq 50$ and able to walk without assistive devices. To analyze trends in prevalence, we combined moderate and severe CP into a moderate-to-severe group. A Z-score for birthweight by gestational age was derived for each child. For Swedish children, Marsal fetal growth standard curves were used; [25] Gardosi fetal growth standard curves were used for children of all other registers. [26]

\section{Statistical methods}

We report descriptive statistics as percentages or as mean with standard deviation (SD). To study changes in characteristics of children with $\mathrm{CP}$ over time, we considered 4 periods: 1980-1984; 1985-1989; 1990-1994, and 1995-1998, and we adjusted on register effect to take account of the fact that the number of registers contributing data differed between the periods. Binary variables were analyzed using the Chi-square test for trend 
adjusting on register, provided that the Chi-square test for non-linearity was not significant. Continuous variables were analyzed using linear regression analyses adjusted for period and register.

Poisson regression was used to investigate trends in prevalence of $\mathrm{CP}$. Given that data were provided by different registers covering varying periods, we followed several steps. Firstly, we analyzed trends in prevalence within each register with a linear term for individual birth year. We tested non-linearity of the trend using polynomial terms for birth years up to third order. Secondly, we used pooled data to investigate trends in Europe. The initial model contained just individual birth years. Addition of a term for register allowed testing for a register effect. Then, adding an interaction term between register and birth year provided a test for variation in trends between registers. We also tested non-linearity of the trend using polynomial terms for birth years up to third order. Likelihood-ratio Chi squared tests were used to compare nested models. The same modeling strategy was used when analyzing time trends by CP subtype and by severity.

To assess the robustness of our results, we performed cross-validation by sequentially removing each register from the model. We verified that the registers responsible for interaction were also those responsible for the main changes in the prevalence estimates when removed sequentially from analysis.

In order to minimize findings that were of statistical significance but little clinical relevance in such a large dataset, the threshold selected for overall analyses was $P<.005$. The threshold for analyses of individual registers data was $P<.05$. We present prevalence rates with Poisson $99 \%$ confidence intervals for pooled data and with $95 \%$ confidence intervals for individual 
registers. Statistical analyses were performed using Stata Statistical software (version 10.0, Stata Corp., College Station, TX, USA). 


\section{RESULTS}

\section{Characteristics of the children with cerebral palsy included in the study}

Fifteen SCPE registers provided data on 7507 children with known birthweight from 1980-1998. Of those, $4002(53 \%)$ were born with birthweight $\geq 2500 \mathrm{~g}$ and were included in the study (Figure 1). The type of CP was spastic in $84.9 \%$ of cases (bilateral in $45.7 \%$, unilateral in 39.2\%), dyskinetic in 9.3\%, and ataxic in 5.8\% (Table 1). Among these children $2290(58.0 \%)$ were male, $3520(91.2 \%)$ were $\geq 37$ weeks gestational age, and $3772(97.4 \%)$ were singletons. Of 2518 mothers with available data, 1697 (67.4\%) were primigravida. At the time of registration, $29.1 \%$ of the children were unable to walk without assistive devices, $30.3 \%$ had severe intellectual impairment, $10.4 \%$ had severe visual impairment, and $1.7 \%$ severe hearing impairment. Nine hundred and forty-five children (23.9\%) were known to have been admitted to a neonatal care unit. Apgar score at five minutes had been recorded since 1990 in four registers, and was available for 761 children. Among them, $610(80.2 \%)$ had an Apgar score $\geq 7$ and $57(7.5 \%)$ scored below 4 .

\section{Change over time in characteristics of children with cerebral palsy and birthweight $\geq 2500 \mathrm{~g}$ (Table 2)}

There was no significant change in the proportion of children with $\mathrm{CP}$ who were female, or from a multiple birth. The mean $\mathrm{Z}$ score for birthweight increased significantly. Mean maternal age increased from 26.7 years to 28.8 years, $P<.001$. The proportion of children with severe intellectual impairment decreased from $33.4 \%$ in $1980-1984$ to $27.9 \%$ in 1995-1998, but the trend did not reach significance. 


\section{Prevalence of cerebral palsy in children with birthweight $\geq 2500 \mathrm{~g}$}

The overall prevalence, including 14 registers, was 1.14 per 1000 births (CI, 1.091.18) during the study period. Prevalence rates in each register are presented in Table 3 . For 12 of them, trends in prevalence were not significant. Two registers from United Kingdom showed significant change in prevalence: an increase was seen in the area covered by Newcastle register, SCPE_C08 $(P=.01)$ whilst a decrease was observed in Oxford register, SCPE_C09 $(P<.001)$.

When analyzing trend in overall prevalence of $\mathrm{CP}$ in Europe, there was a significant interaction between register and birth year $(P<.001)$. This interaction indicates that the trend was heterogeneous across registers and therefore does not allow reporting of an overall trend for all registers. After removing the two registers (Newcastle and Oxford) which showed a significant trend in prevalence, the interaction was no longer significant $(P=.83)$. We therefore analyzed trends pooling data from the 12 remaining registers whilst data from Oxford and Newcastle were analyzed separately. The overall prevalence for the 12 registers was 1.10 per 1000 live births (1.05-1.15) from 1980 to $1998 ; 1.16$ per 1000 live births (CI, 0.88-1.48) in 1980 and 0.99 per 1000 live births (CI, 0.80-1.20) in 1998 (Figure 2). The decrease was not significant $(P=.14)$. The prevalence of bilateral spastic CP decreased significantly from 0.58 (CI, 0.41-0.80) in 1980 to 0.33 (CI, 0.22-0.46) in $1998, P<.001$. At the same time, the prevalence of unilateral spastic $\mathrm{CP}$ increased from 0.37 (CI, $0.23-0.58)$ to $0.46(\mathrm{CI}$, 0.34-0.62), $P=.004$. There was no significant change in the prevalence of dyskinetic forms over the period, $P=.37$. The prevalence of moderate-to-severe $\mathrm{CP}$ decreased from 0.52 (CI, $0.34-0.75)$ to $0.42(\mathrm{CI}, 0.30-0.57)$ but the trend was not significant $(P=.009)$. The prevalence of mild cases was stable $(P=.67)$ with a mean rate of 0.53 per 1000 live births $(\mathrm{CI}, 0.50-0.56)$. 
In Newcastle, the prevalence increased significantly (Figure 3, $P=.01$ ), mainly because of the increase in bilateral spastic type $(P=.005)$ from 0.54 per $1000(\mathrm{CI}$, 0.18-1.27) to 0.71 (CI, 0.44-1.08). There were no significant changes in rates of other $\mathrm{CP}$ subtypes or in the moderate-to-severe group. In Oxford, the prevalence decreased significantly (Figure $3, P<.001$ ), mainly due to a decrease in unilateral spastic type from 0.37 (CI, 0.18-0.66) to $0.16(\mathrm{CI}, 0.05-0.37), P=.006$. In this register, there was a "borderline" decrease in bilateral spastic forms, $P=.06$ and a decrease in the prevalence of moderate-tosevere forms, $P=.02$.

During the same period covered by our study, i.e. between 1980 and 1998, there was a significant reduction in neonatal mortality of nearly $50 \%$ from 1.7 (CI, 1.4-2.1) to 0.9 (CI, 0.7-1.1) per 1000 NBW live births in the areas covered by registers which contributed data throughout $(n=9)$. 


\section{DISCUSSION}

The SCPE population-based registers and surveys feed a unique population-based database for Europe using standardized procedures to include and classify children with CP. In the present study, we found that in 12 out of 14 registers, there was no significant change in prevalence of CP in children with birthweight $\geq 2500 \mathrm{~g}$ born between 1980 and 1998 . Our findings issuing from population-based data are unlikely to be influenced by a selection bias typically encountered in hospital-based studies. And this result is in agreement with previous studies conducted outside Europe. A recent report from the Western Australia cerebral palsy register [4] showed stable trends in prevalence of CP in NBW children, with a prevalence slightly higher than we observed (1.55 per 1000 live births in $1980-1984$ to 1.62 in 1995 1999). A study from California, USA, also reported a stable prevalence of CP in term children of 1.1 per 1000 live births in 1991-2002.[17] Robustness of our results was assessed in analyzing prevalence rates and trends of $\mathrm{CP}$ in children born at term ( $\geq 37$ gestational age) in the 11 registers able to provide population data by gestational age. Results were very similar to those observed on NBW children (data not shown). Obviously, data quality of the SCPE common database remains dependent on the quality of data provided by the contributing registers. Some of them have already shown the reliability of their data in previous studies, [27-30] and continuous data quality improvement work is being performed at the network level.

The clinical profile of children with CP was generally stable over time. However, there was a non-significant trend toward a decrease in the frequency of associated impairments, i.e. severe intellectual impairment and, in the last period, severe visual impairment. Twenty-four percent of the children were known to have been admitted to a 
neonatal care unit. This percentage may be an underestimate due to numerous missing data in three registers. Two recent studies in the USA and Australia showed that $30 \%$ to $35 \%$ of children born at term who developed $\mathrm{CP}$ were admitted to a neonatal intensive care unit (NICU).[17, 31] Whilst most moderate (1500 g to $2499 \mathrm{~g}$ ) or very low birthweight children are born in maternity with NICU, this is not observed for NBW children. The significant decrease in neonatal mortality for NBW children reflects advances in obstetric and neonatal care between 1980 and 1998 and it is reassuring that this was not accompanied by a rise in $\mathrm{CP}$ prevalence. Probably the impact on morbidity of these improvements in neonatal care is first seen in children born in maternity with NCIU. The significant decrease in CP prevalence seen in very low birthweight [32] children is yet to be observed in NBW children.

Several explanations can be proposed regarding the different trends observed in two UK registers. In Oxford, the decline in prevalence was particularly marked for births after 1996. We can not exclude a true decline in the number of children with CP in this area. However, this was more likely the result of under-ascertainment due to the unwillingness of clinicians to provide data for the CP register following the enactment of the 1998 Data Protection Act. Both in Scotland and Liverpool registers have ceased collecting data because of these difficulties. Moreover, the register in Northern Ireland was allowed to move to a nonconsent based system because of incompleteness when seeking consent. The explanation for the observed increase in Newcastle may be related to the expansion of its catchment area from 1991 births. If the prevalence for the additional area covered since 1991 was higher than the pre-1991 area, the inclusion of this additional area may have increased the overall prevalence. This explanation is supported by the stability of prevalence over the period 1964-1993 in the initial catchment area.[33] 
We observed a significant decrease in the bilateral spastic group, the most common subtype, of more than $40 \%$. At the same time, there was an increase in unilateral spastic subtype. It is unlikely that the changes in prevalence of unilateral and bilateral CP types resulted from classification bias between the two subtypes. A reliability study performed in 2003 within the SCPE network showed more discrepancies between bilateral spastic and dyskinetic CP than between bilateral and unilateral spastic CP.[34] However, we do not believe that the trends reflect a different approach to classification of dyskinetic and bilateral spastic as there was no significant change in the prevalence of dyskinetic CP. In addition, if the increase in unilateral spastic $\mathrm{CP}$ was related to improved ascertainment, an overall increase in milder cases could be expected and this was not observed. Few papers have analyzed trends over time by CP subtypes and birthweight and usually it is proportions of subtypes that are compared, not prevalence. ${ }^{9}$ [33] In our study, we found a non-significant increase in prevalence of dyskinetic forms. A recent study, also based on the SCPE common database, reported a significant increase in the prevalence of dyskinetic $\mathrm{CP}$ among NBW children for the period 1976-1984, followed by a plateau. [35] Our analysis covered a later period, 1980-1998, and confirmed the leveling off of prevalence of dyskinetic CP.

The changes observed in spastic subgroups do not have a straightforward interpretation. We agree with recent comment of Pharoah, regarding the fact that trends in incidence, not prevalence are crucial to determining etiology. [36] Nevertheless, few hypothesis might be mentioned. The decrease in prevalence of bilateral spastic CP may be explained by improvements in neonatal care, but there is no obvious reason for the increase in unilateral spastic CP. Neuro-imaging studies $[10,11]$ suggest that slightly different patterns of brain abnormalities are observed in unilateral and bilateral spastic CP. Thus, it might be possible that prevention has affected the two subtypes differently. 
In conclusion, this study was the first to analyze European trends in prevalence of CP in children with birthweight $\geq 2500 \mathrm{~g}$. We showed that the prevalence was stable in spite of decreasing neonatal mortality. The reduction in prevalence of bilateral spastic $\mathrm{CP}$, suggests that prevention of the more severe forms may be occurring. Data were available for children born until 1998, thus ongoing monitoring of the trends, including trends in the different subtypes, is necessary. 


\section{ACKNOWLEDGMENTS}

We thank all SCPE participants: C Cans, S Rey (RHEOP, Grenoble, FR), J Chalmers (ISDSHS, Edinburgh, UK), V McManus, A Lyons (Lavanagh Centre, Cork, IE), J Parkes, H Dolk (Belfast, UK), P Uvebrant, K Himmelmann (Göteborg University, Göteborg, SW), A Colver (University of Newcastle, Newcastle, UK), J Kurinczuk, G Surman (NPEU, Oxford, UK), I Krägeloh-Mann, V Horber (Tübingen University, Tübingen, DE), MJ Platt (University of Liverpool, Liverpool, UK), P Udall, S Holst-Ravn (NIPH, Copenhagen, DK), MG Torrioli, S Matricardi (Lazio Cerebral Palsy Register, Rome, IT), G Andersen, A Meberg (CPRN, Tonsberg, NO), M Bottos (Bologna, IT), G Gaffney (Galway, IE), J De la Cruz, C Pallas (DIMAS-SAMID, Madrid, SP).

\section{FUNDING}

This work was supported by grants from the European Commission [Research DGQLG5-2001-30133, DGSANCO-2003-3131]. Geraldine Surman was funded by the Policy Research Programme in the Department of Health, England and the views expressed are not necessarily those of the Department. 


\section{REFERENCES}

1. Himpens E, Van den Broeck C, Oostra A, Calders P, Vanhaesebrouck P. Prevalence, type, distribution, and severity of cerebral palsy in relation to gestational age: a meta-analytic review. Dev Med Child Neurol 2008;50:334-40.

2. Prevalence and characteristics of children with cerebral palsy in Europe. Dev Med Child Neurol 2002;44:633-40.

3. Grether JK, Cummins SK, Nelson KB. The California Cerebral Palsy Project. Paediatr Perinat Epidemiol 1992;6:339-51.

4. Watson L, Blair E., Stanley F. Report of the Western Australian cerebral palsy register. To birth year 1999. Perth: Institute for Child Health Research, 2006.

5. Liu JM, Li S, Lin Q, Li Z. Prevalence of cerebral palsy in China. Int J Epidemiol 1999;28:949-54.

6. Himmelmann K, Beckung E, Hagberg G, Uvebrant P. Gross and fine motor function and accompanying impairments in cerebral palsy. Dev Med Child Neurol 2006;48:417-23.

7. Hemming K, Colver A, Hutton JL, Kurinczuk JJ, Pharoah PO. The influence of gestational age on severity of impairment in spastic cerebral palsy. J Pediatr 2008;153:203-8.

8. Surman G, Hemming K, Platt MJ, et al. Children with cerebral palsy: severity and trends over time. Paediatr Perinat Epidemiol 2009;23:513-21.

9. Hagberg B, Hagberg G. The origins of cerebral palsy. In: David T, ed. Recent advances in Paediatrics Vol. 11. London: Churchill Livingstone, 1993:67-83.

10. Krageloh-Mann I, Horber V. The role of magnetic resonance imaging in elucidating the pathogenesis of cerebral palsy: a systematic review. Dev Med Child Neurol 2007;49:14451.

11. Ashwal S, Russman BS, Blasco PA, et al. Practice parameter: diagnostic assessment of the child with cerebral palsy: report of the Quality Standards Subcommittee of the American 
Academy of Neurology and the Practice Committee of the Child Neurology Society. Neurology 2004;62:851-63.

12. Cans C, De-la-Cruz J, Mermet MA. Epidemiology of cerebral palsy. Paediatr Child Health 2008;18:393-8.

13. Paneth N, Hong T, Korzeniewski S. The descriptive epidemiology of cerebral palsy. Clin Perinatol 2006;33:251-67.

14. Drummond PM, Colver AF. Analysis by gestational age of cerebral palsy in singleton births in north-east England 1970-94. Paediatr Perinat Epidemiol 2002;16:172-80.

15. Topp M, Uldall P, Greisen G. Cerebral palsy births in eastern Denmark, 1987--90: implications for neonatal care. Paediatr Perinat Epidemiol 2001;15:271-7.

16. Dolk H, Parkes J, Hill N. Trends in the prevalence of cerebral palsy in Northern Ireland, 1981-1997. Dev Med Child Neurol 2006;48:406-12.

17. Wu YW, Croen LA, Shah SJ, Newman TB, Najjar DV. Cerebral palsy in a term population: risk factors and neuroimaging findings. Pediatrics 2006;118:690-7.

18. Winter S, Autry A, Boyle C, Yeargin-Allsopp M. Trends in the prevalence of cerebral palsy in a population-based study. Pediatrics 2002;110:1220-5.

19. Himmelmann K, Hagberg G, Beckung E, Hagberg B, Uvebrant P. The changing panorama of cerebral palsy in Sweden. IX. Prevalence and origin in the birth-year period 1995-1998. Acta Paediatr 2005;94:287-94.

20. Sigurdardottir S, Thorkelsson T, Halldorsdottir M, Thorarensen O, Vik T. Trends in prevalence and characteristics of cerebral palsy among Icelandic children born 1990 to 2003. Dev Med Child Neurol 2009;51:356-63.

21. Surveillance of cerebral palsy in Europe: a collaboration of cerebral palsy surveys and registers. Surveillance of Cerebral Palsy in Europe (SCPE). Dev Med Child Neurol 2000;42:816-24. 
22. Cans C, Dolk H, Platt MJ, Colver A, Prasauskiene A, Krageloh-Mann I.

Recommendations from the SCPE collaborative group for defining and classifying cerebral palsy. Dev Med Child Neurol Suppl 2007;109:35-8.

23. Platt MJ, Krageloh-Mann I, Cans C. Surveillance of cerebral palsy in europe: reference and training manual. Med Educ 2009;43:495-6.

24. Beckung E, Hagberg G, Uldall P, Cans C. Probability of walking in children with cerebral palsy in Europe. Pediatrics 2008;12:187-92.

25. Marsal K, Persson PH, Larsen T, Lilja H, Selbing A, Sultan B. Intrauterine growth curves based on ultrasonically estimated foetal weights. Acta Paediatr 1996;85:843-8.

26. Gardosi J, Mongelli M, Wilcox M, Chang A. An adjustable fetal weight standard. Ultrasound Obstet Gynecol 1995;6:168-74.

27. Topp M, Langhoff-Roos J, Uldall P. Validation of a cerebral palsy register. J Clin Epidemiol 1997;50:1017-23.

28. Johnson A, King R. Can routine information systems be used to monitor serious disability? Arch Dis Child 1999;80:63-6.

29. Parkes J, Dolk H, Hill N. Does the Child Health Computing System adequately identify children with cerebral palsy? J Public Health Med 1998;20:102-4.

30. Guillem P, Lavergne C, Cans C. How to calculate the completeness of ascertainment of a morbidity register? Example of the Isere childhood handicap register in Grenoble, France. Rev Epidemiol Sante Publique 2000;48:41-51.

31. Mcintyre S, Blair E, Badawi N, Watson L. The changing picture of cerebral palsy for those born at term: 16 years of population data. Dev Med Child Neurol 2009;51(Suppl.2):190. 
32. Platt MJ, Cans C, Johnson A, et al. Trends in cerebral palsy among infants of very low birthweight $(<1500 \mathrm{~g})$ or born prematurely ( $<32$ weeks) in 16 European centres: a database study. Lancet 2007;369:43-50.

33. Colver AF, Gibson M, Hey EN, Jarvis SN, Mackie PC, Richmond S. Increasing rates of cerebral palsy across the severity spectrum in north-east England 1964-1993. The North of England Collaborative Cerebral Palsy Survey. Arch Dis Child Fetal Neonatal Ed 2000 ;83:F7F12.

34. Gainsborough M, Surman G, Maestri G, Colver A, Cans C. Validity and reliability of the guidelines of the surveillance of cerebral palsy in Europe for the classification of cerebral palsy. Dev Med Child Neurol 2008;50:828-31.

35. Himmelmann K, McManus V, Hagberg G, Uvebrant P, Krageloh-Mann I, Cans C.

Dyskinetic cerebral palsy in Europe: trends in prevalence and severity. Arch Dis Child 2009;94:921-6.

36. Pharoah PO. Dyskinetic cerebral palsy in Europe: trends in prevalence and severity, on behalf of the SCPE Collaboration. Arch Dis Child 2009;94:917-8. 
Table 1. Characteristics of children with cerebral palsy and birthweight $\geq 2500 \mathrm{~g}$, summary from 14 SCPE registers ${ }^{\mathrm{a}}(\mathrm{n}=3948)$.

$\mathrm{N}=3948$

$(\%)$

Male

58.0

Gestational age (2.2\% missing)

$<37$ weeks

37-41 weeks

$>41$ weeks

Maternal age in years, mean (SD) (28.3\% missing)

Multiple births (1.9\% missing)

CP type (3.9\% missing)

Bilateral spastic

Unilateral spastic

Dyskinetic

Ataxic

Walking ( $8.3 \%$ missing)

Without assistive devices

With assistive devices

Unable to walk

Epilepsy (15.0\% missing)

Severe intellectual impairment (IQ<50) (13.1\% missing)

Known to have a severe visual impairment

Known to have a severe hearing impairment

Known to have been admitted to a neonatal care unit

Severity (7.7\% missing)

Severe (IQ<50 and unable to walk, even with assistive devices)

Moderate (IQ $<50$ and able to walk or $\mathrm{IQ} \geq 50$ and unable to walk without assistive devices)

Mild (IQ $\geq 50$ and able to walk without assistive devices)

50.5

${ }^{\mathrm{a}}$ Data from Tübingen registering only bilateral spastic cases were excluded 
Table 2. Changes over time in characteristics of children with cerebral palsy and birthweight $\geq 2500 \mathrm{~g}$. From 14 SCPE registers $(n=3948)$.

\begin{tabular}{lccccc}
\hline Characteristics $^{\text {a }}$ & $1980-1984$ & $1985-1989$ & $1990-1994$ & $1995-1998$ & Test for linear trend $^{\mathrm{b}}$ \\
& $n=758$ & $n=1252$ & $n=1057$ & $n=881$ & $P$ value \\
\hline Female, n (\%) & $344(45.4)$ & $530(42.3)$ & $427(40.4)$ & $357(40.5)$ & .06 \\
Maternal age over 34 years, n (\%) & $51(9.5)$ & $91(10.5)$ & $111(15.2)$ & $111(15.7)$ & .001 \\
Multiple birth, n (\%) & $21(2.9)$ & $22(1.8)$ & $30(2.8)$ & $26(3.0)$ & .15 \\
Z score, mean (SD) & $-0.25(1.22)$ & $-0.15(1.31)$ & $-0.06(1.36)$ & $0.08(1.42)$ & $<.001$ \\
Unable to walk, even with aids, n (\%) & $203(28.2)$ & $380(30.9)$ & $286(27.8)$ & $185(28.8)$ & .77 \\
Severe intellectual impairment, n (\%) & $226(33.4)$ & $303(29.5)$ & $300(30.9)$ & $211(27.9)$ & .05 \\
Severe visual impairment, n (\%) & $78(10.6)$ & $140(11.9)$ & $129(12.3)$ & $65(7.4)$ & .29 \\
Severe hearing impairment, n (\%) & $8(1.1)$ & $30(2.4)$ & $17(1.6)$ & $12(1.4)$ & .56 \\
Epilepsy, n (\%) & $214(37.9)$ & $343(35.2)$ & $391(38.6)$ & $291(36.2)$ & .98 \\
Severe-to-moderate CP, n (\%) & $350(50.2)$ & $598(51.5)$ & $474(47.8)$ & $383(48.2)$ & .42
\end{tabular}

\footnotetext{
${ }^{a}$ Mother's age was available for 2831 children, multiple birth status for 3872 children, Z score for 3763 singleton children, ability to walk for 3621 children, intellectual impairment level for 3433 children, epilepsy for 3357 children. Percentages are calculated using the total known cases for each characteristic as denominators

${ }^{\mathrm{b}}$ Test for linear trend was adjusted for register
} 
Table 3. Children with cerebral palsy and birthweight $\geq 2500 \mathrm{~g}$ by SCPE register: number of cases and prevalence by period.

\begin{tabular}{|c|c|c|c|c|c|c|}
\hline & Period covered & Number of cases & $\begin{array}{c}\text { Prevalence rate }^{\mathrm{a}} \\
\text { 1980-1984 }\end{array}$ & $\begin{array}{c}\text { Prevalence rate }^{\mathrm{a}} \\
1985-1989\end{array}$ & $\begin{array}{c}\text { Prevalence rate }^{\mathrm{a}} \\
\text { 1990-1994 }\end{array}$ & $\begin{array}{c}\text { Prevalence rate }^{\mathrm{a}} \\
1995-1998\end{array}$ \\
\hline Grenoble, France (SCPE_C01) & $1980-1998$ & 234 & 0.88 & 0.99 & 1.21 & 0.80 \\
\hline Edinburgh, UK (SCPE_C03) & 1984-1989 & 301 & 0.83 & 0.83 & - & - \\
\hline Cork, Ireland (SCPE_C04) & $1986-1998$ & 89 & - & 0.96 & 0.93 & 0.91 \\
\hline Belfast, UK (SCPE_C05) & $1981-1998$ & 472 & 1.21 & 1.04 & 1.16 & 1.13 \\
\hline Gothenburg, Sweden (SCPE_C06) & $1980-1998$ & 474 & 1.32 & 1.32 & 1.19 & 1.16 \\
\hline Newcastle, UK (SCPE_C08) & $1980-1998$ & 501 & 1.09 & 1.27 & 1.42 & 1.55 \\
\hline Oxford, UK (SCPE_C09) & 1984-1998 & 543 & 1.28 & 1.40 & 1.00 & 0.88 \\
\hline Tübingen, Germany $\left(\mathrm{SCPE} \_\mathrm{C} 10\right)^{\mathrm{b}}$ & $1980-1986$ & 54 & & & & \\
\hline Liverpool, UK (SCPE_C11) & $1980-1989$ & 340 & 1.23 & 1.26 & - & - \\
\hline Copenhagen, Denmark (SCPE_C12) & $1980-1998$ & 738 & 1.46 & 1.30 & 1.25 & 1.29 \\
\hline Rome, Italy (SCPE_C13) & $1983-1998$ & 40 & 1.54 & 1.20 & 1.24 & 0.62 \\
\hline Tonsberg, Norway (SCPE_C15) & $1991-1998$ & 98 & - & - & 1.05 & 0.89 \\
\hline Bologna, Italy (SCPE_C16) & $1991-1996$ & 25 & & & 0.74 & 0.69 \\
\hline Galway, Ireland (SCPE_C17) & 1990-1998 & 62 & & & 0.83 & 1.16 \\
\hline Madrid, Spain (SCPE_C18) & 1991-1998 & 31 & & & 0.65 & 0.72 \\
\hline
\end{tabular}

${ }^{\text {a }}$ Prevalence rates are presented per 1000 live births

${ }^{\mathrm{b}}$ The SCPE_C10 register included only children with bilateral spastic cerebral palsy. 


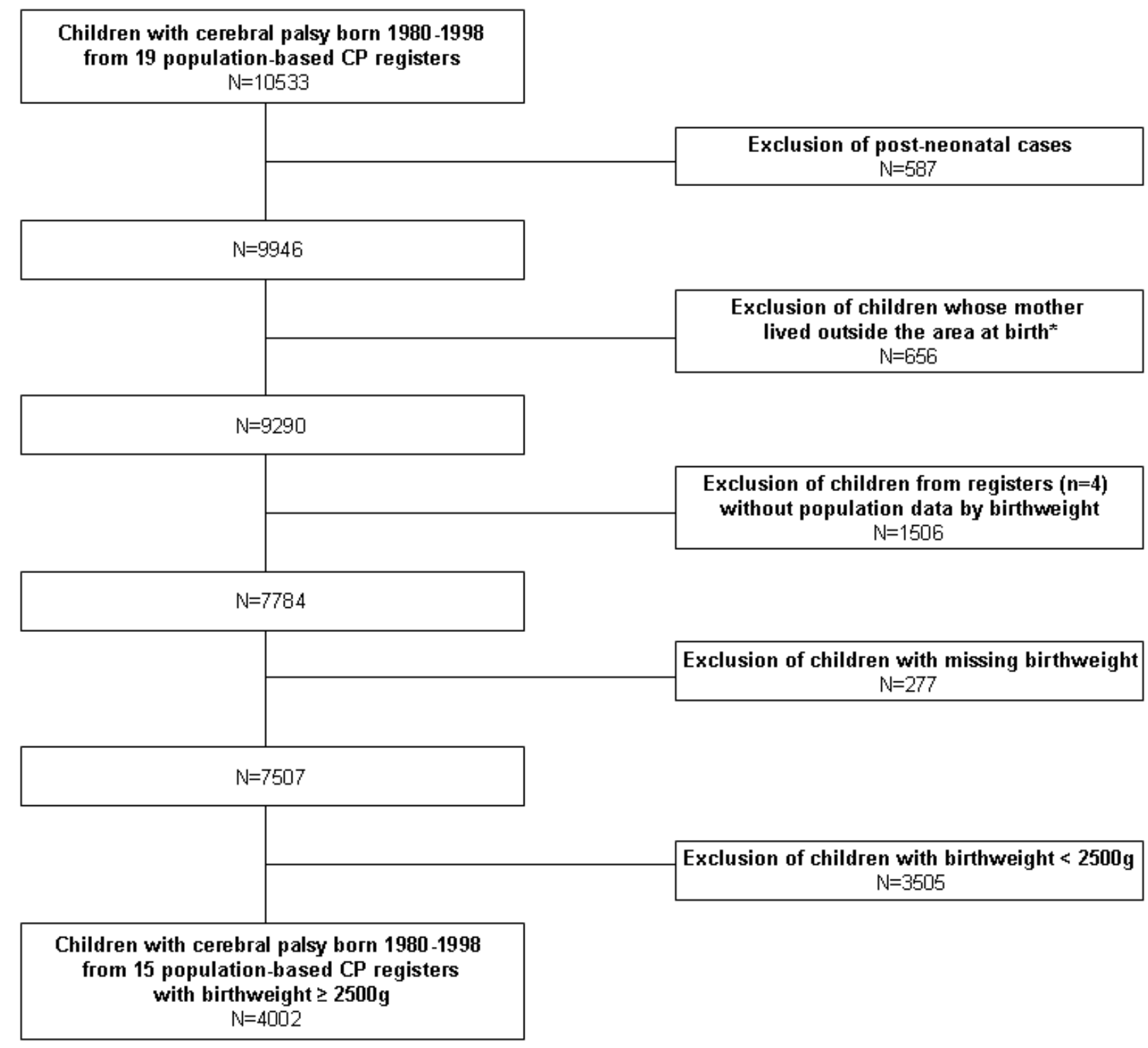




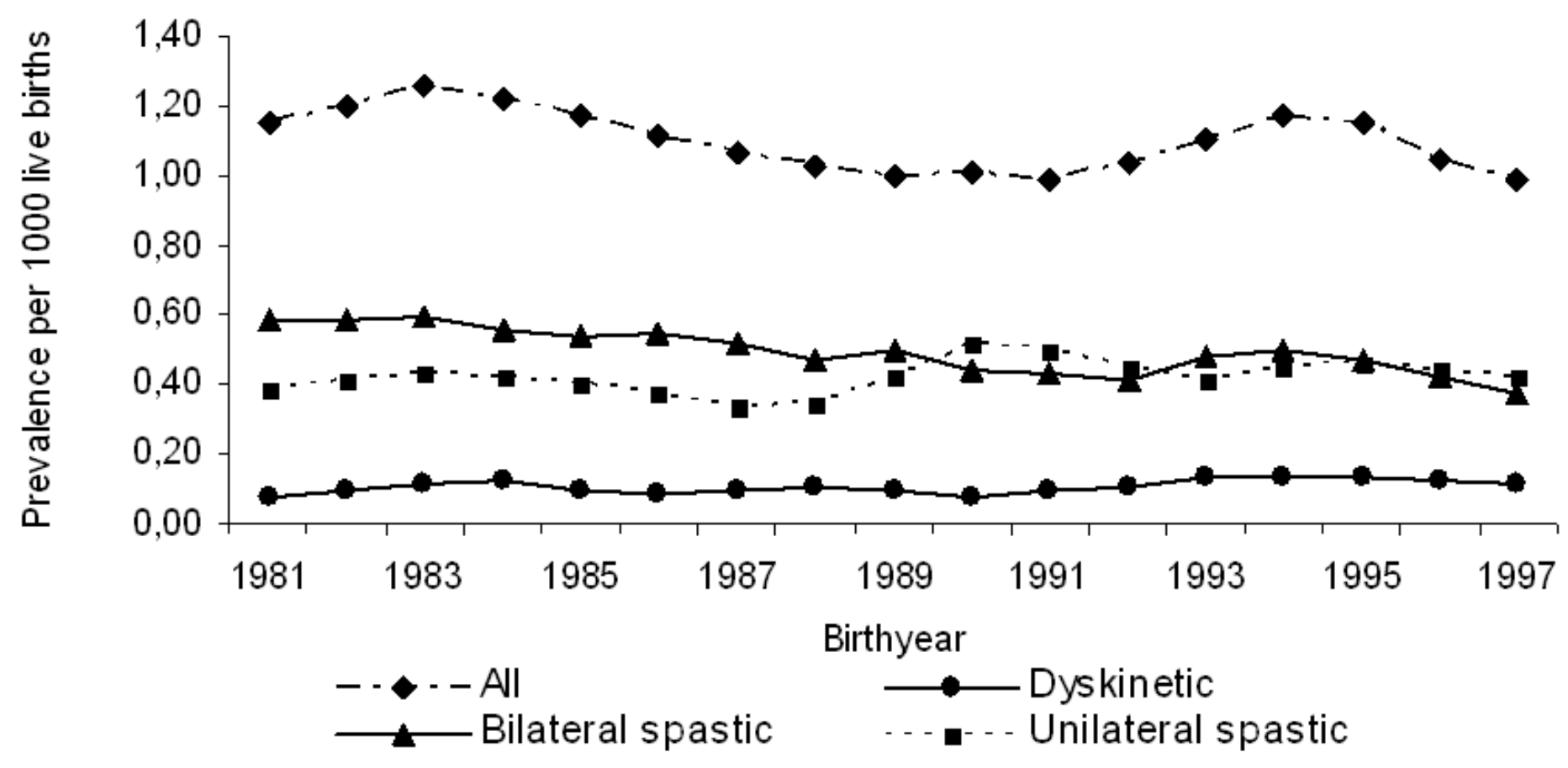






-... Newcastle $\quad \ldots$ Oxford 